M. Pawlitzki ${ }^{1}$, U. K. Zettl' ${ }^{2}$, T. Ruck ${ }^{1}$, L. Rolfes ${ }^{1}$, H.-P. Hartung ${ }^{3}$, S. G. Meuth ${ }^{1}$

${ }^{1}$ Klinik für Neurologie mit Institut für Translationale Neurologie, Universitätsklinikum Münster, Münster, Deutschland

${ }^{2}$ Klinik für Neurologie, Sektion für Neuroimmunologie, Universität Rostock, Rostock, Deutschland

${ }^{3}$ Klinik für Neurologie, Medizinische Fakultät, Heinrich-Heine-Universität Düsseldorf, Düsseldorf, Deutschland

\title{
Risiken und Chancen von Immuntherapien in Zeiten der Coronavirus-2019-Pandemie
}

\section{Einleitung}

Der rasche pandemische Ausbruch der Coronaviruserkrankung 2019 (COVID-19) stellt eine der bedeutendsten globalen Herausforderungen des 21. Jahrhunderts dar. Die klinischen Präsentationen variieren von asymptomatischen und leichten klinischen Symptomen bis hin zum akuten Lungenversagen (ARDS) und dem damit verbundenen Mortalitätsrisiko [1]. Zum Zeitpunkt der Erstellung dieses Artikels waren weltweit mehr als 5 Mio. Menschen infiziert und mehr als 300.000 Menschen sind bereits an der Coronavirus-2-Infektion (SARS-CoV-2-Infektion) verstorben. Trotz intensiver Bemühungen ist bisher kein gesichertes Therapiekonzept, inklusive einer Impfung, in Aussicht [2]. Dies ist v. a. in Hinblick auf Risikopopulationen von essenzieller Bedeutung. Derzeit existieren in diesem Zusammenhang bis auf wenige Fallserien keine ausreichenden Daten hinsichtlich des Risikos einer SARS-CoV-2-Infektion und des Krankheitsverlaufs bei Patienten mit neuroimmunologischen Erkrankungen [3, 4]. Insbesondere kann bei bereits vorliegender krankheitsassoziierter schwerer physischer Behinderung von einem erhöhten Risiko hinsichtlich des Auftretens von schweren Verläufen ausgegangen werden [5]. Des Weiteren stellen krankheitsmodifizierende, immunsuppressive und immunmodulatorische Therapien aufgrund ihres Einflusses auf das Immunsystem, ein potenzielles Risiko dar, wie die Erfahrungen mit anderen Virusinfektionen zeigen [6]. Eine Stabilisierung der zugrunde liegenden Erkrankung durch Immuntherapeutika kann auf der anderen Seite die Morbidität und damit auch das Risiko für eine Infektion reduzieren [5]. Die Ungewissheit über die Anwendung von Immuntherapien wird durch die derzeit zahlreichen, aber uneinheitlichen Empfehlungen von nationalen und internationalen Gesellschaften für verschiedene neuroimmunologische Erkrankungen verdeutlicht.

Ähnlich wie bei anderen schweren Virusinfektionen umfassen die Krankheitsmerkmale von COVID-19 zwei kritische Phasen, die virale sowie die Wirtsantwortphase, in denen das Zusammenspiel zwischen pro- und antiinflammatorischen Mechanismen des Wirts eine wichtige Rolle für den krankheitsbedingten Verlauf zu spielen scheint (Abb. 1a; [7-9]). Obwohl ei-

\section{Redaktion}

F. Block, Schwerin

S. G. Meuth, Münster

DGNeurologie 2020 · 3 (4): 285-297

https://doi.org/10.1007/s42451-020-00205-6

Online publiziert: 10. Juni 2020

(c) Springer Medizin Verlag GmbH, ein Teil von Springer Nature 2020 ne adäquate und schnelle Immunantwort die Virusvermehrung und die zytopathischen Effekte reduziert, scheint die virusinduzierte erhöhte Wirtsimmunität jedoch umgekehrt schwere pulmonale Komplikationen erst zu bedingen (Abb. 1b; [10-12]).

Während das erhöhte Infektionsrisiko unter immunmodulatorischen Therapien ein Problem darstellen könnte, mehren sich die Hinweise darauf, dass die Anwendung einiger Immuntherapien auch positive Auswirkungen auf die Regulierung übermäßiger Entzündungsreaktionen im späten Infektionsstadium haben könnte [6]. Die zunehmende Erfahrung und Erforschung von Immuntherapien und deren unterschiedliche Ansätze sollten daher in Zeiten von COVID-19 genutzt werden, um das Risiko für die Patienten zu verringern, aber auch die Chancen einer Immuntherapie zu identifizieren $[12,13]$.

\section{COVID-19 und die Rolle der Inflammation}

Der SARS-CoV-2 Virus gehört zu der Gruppe der EinzelstrangRNA-Viren und ist das dritte bekannte hochpathogene zoonotische $\mathrm{CoV}$ in den letzten 2 Jahrzehnten nach SARS-CoV und MERS-CoV [14]. Trotz der großen Zahl aktueller Publikationen zu COVID-19 werden weiterhin Schlussfolgerungen bezüglich der Pathogenese zu einem Großteil aus klinischen Beobachtungen und experimentellen Studien mit SARS-CoV und MERS-CoV gezogen [14-18]. Im Hinblick auf die beiden unterschiedlichen Krankheitsstadien von COVID-19 stehen verschiedene immunologische Kaskaden im Vordergrund, die potenzielle Behandlungsziele bieten (Abb. 1b). In der initialen viralen Antwortphase von COVID-19 erfolgen die rezeptorvermittelte virale Anheftung und der Eintritt von SARSCoV-2 in die Zielzellen insbesondere im Respirationstrakt [20, 21]. Die rasche virale Replikation führt zu massiven zytopathischen und entzündlichen Effekten in den Wirtszellen. Die Immunantwort des Wirts erfolgt dabei über Zellen des angeborenen und adaptiven Immunsystems. Die früh synthetisierten und freigesetzten Virusproteine werden hauptsächlich von endosomalen Toll-like-Rezeptoren des infizierten Gewebes oder von Makrophagen, neutrophilen Granulozyten und dendritische Zellen erkannt, was zur Aktivierung intrazellulärer Rezeptoren sowie von Transmembranproteinen führt [7, 22]. Letztere Mechanismen laufen über die Aktivierung von Proteinkinasen zusammen, die ihrerseits die Transkription und Sekretion von proinflammatorischen Interleukinen (IL) und Chemokinen stimulieren. Neben der Hemmung der viralen Replikation induziert die Chemokinsekretion die Aktivierung des adaptiven Immunsystems [7, 23, 24]. Dieses wird in erster Linie durch die T-Zell-Immunantwort angetrieben. Insbesondere zytotoxische T-Zellen erkennen zytosolische, gewöhnlich endogen syntheti- 


\section{Risiken und Chancen von Immuntherapien in Zeiten der Coronavirus-2019-Pandemie}

\section{Zusammenfassung}

Immuntherapien stellen die essenzielle Grundlage der Behandlung von neuroinflammatorischen Erkrankungen dar. In Zeiten der Coronavirus2019 (COVID-19)-Pandemie ergibt sich im klinischen Alltag jedoch zunehmend die Frage, ob eine Immuntherapie bei neurologischen Patienten aufgrund des potenziellen Infektionsrisikos eingeleitet, intensiviert, pausiert oder gar beendet werden sollte. Unsicherheit besteht $v$. a. deshalb, weil verschiedene nationale und internationale
Fachgesellschaften diesbezüglich unterschiedliche Empfehlungen veröffentlichten. In diesem Artikel soll ein Überblick über die Wirkmechanismen von Immuntherapien und den daraus abzuleitenden Infektionsrisiken in Bezug auf COVID-19 (durch den Coronavirus verursachte Erkrankung) gegeben werden. Potenzielle Chancen und vorteilhafte Effekte einzelner Substrate in der Akuttherapie von COVID19 werden diskutiert.

\section{Risks and possibilities of immunotherapy in times of the coronavirus 2019 pandemic}

\section{Abstract}

Immunotherapies form the essential basis of treatment for neuroinflammatory disease. However, in times of the coronavirus 2019 (COVID19) pandemic, the question is increasingly arising in clinical routine as to whether immunotherapy should be initiated, intensified, paused, or even discontinued in neurological patients due to the risk of infection. Uncertainty is caused primarily due to the fact that a number of national and international scientific medical societies have published differing recommendations in this regard. This article provides an overview of the mechanisms of action of immunotherapies and the resulting risks of infection with COVID-19. Potential opportunities and beneficial effects of individual substrates in the acute treatment of COVID-19 are discussed. sierte virale Peptide, die von MHC-Klasse-I-Molekülen präsentiert werden. $\mathrm{CD}^{+}{ }^{+} \mathrm{T}-$ Zellen attackieren infizierte Zellen direkt und initiieren eine weitere Zytokinsekretion, die die Phagozytose durch (Lungen)makrophagen aktiviert [25].

Bei den meisten COVID-19-Patienten führt diese primäre Immunantwort zu einer Verringerung der Virusaktivität, gefolgt von einer zunehmenden Regulierung der Entzündungsreaktion [8]. Die größere Herausforderung stellt jedoch das Ausmaß der sekundären Phase der Entzündung bei einigen Patienten dar, welche durch einen massiven Zytokinsturm mit Zytokinfreisetzung und einer Leukozyteninfiltration in das bereits geschädigte, aber auch in das gesunde Lungengewebe gekennzeichnet ist (Abb. 1b; [12]). Gegenwärtig werden verschiedene, durch das Virus fehlgesteuerte Immunabwehrmechanismen des Wirts diskutiert. Beispielsweise scheinen die im Verlauf gebildeten, das Virus neutralisierenden Antikörper die proinflammatorische Makrophagenakkumulation und die Produktion von Matrixmetalloproteinasen, Leukotrienen und proinflammatorischen Zytokinen zu fördern [26]. Darüber hinaus führt die antikörpervermittelte Aktivierung des Komplementsystems zur Produktion von Chemokinen und zur Invasion von Granulozyten und Lymphozyten, die die Schädigung des Lungengewebes weiter verstärken (Abb. 1b; [17]).

Letztlich führt das Zusammenspiel mehrerer Immunreaktionen $\mathrm{zu}$ einem progredienten Gewebeschaden, der wiederum $\mathrm{zu}$ einer erneuten Freisetzung von inflammatorischen Zytokinen führt. Die Unterbrechung dieser sich selbst erhaltenden Inflammationskaskade stellt daher einen potenziellen Therapieansatz dar.

\section{Wirkmechanismen von Immuntherapien unter dem Aspekt von COVID-19}

\section{Interferenz mit der DNA-Synthese}

Azathioprin, Methotrexat und Cyclophosphamid sind seit langem etablierte Therapien z. B. bei Myasthenia gravis (MG), Neuromyelitis-optica-Spektrumserkrankungen (NMOSD), idiopathischen entzündlichen Myopathien (IIM), der primären Angiitis des zentralen Nervensystems (PACNS), entzündlichen Neuropathien sowie bei Autoimmunenzephalitiden und rheumatologischen Erkrankungen. Während Azathioprin und Methotrexat hauptsächlich zu Beginn der jeweiligen neuroinflammatorischen Erkrankung und über einen längeren Zeitraum hinweg eingesetzt werden, ist Cyclophosphamid initial bei schweren Krankheitsverläufen indiziert [27]. Mitoxantron, ein DNA-Interkalator und Topoisomerasehemmer vom Typ II, ist ein weiteres klassisches Immunsuppressivum, welches bei der sekundär progredienten multiplen Sklerose (MS), bei therapierefraktärer schubförmiger remittierender MS (RRMS) sowie bei NMOSD eingesetzt wird [28]. Aufgrund der Wirkungsweise ist mit einer anhaltenden Lymphopenie unter diesen Therapien zu rechnen, was mit einem allgemein erhöhten Infektionsrisiko verbunden ist [27, 29-31].

Teriflunomid ist ein zugelassenes Immunsuppressivum für die RRMS. Es hemmt reversibel die Dihydroorotatdehydrogenase, die insbesondere von Lymphozyten exprimiert wird, und damit die Pyrimidinsynthese [32]. Obwohl eine Lymphopenie in ca. $15 \%$ der behandelten Fälle auftritt, war die Inzidenz von Infektionen zwischen mit Plazebo bzw. Teriflunomid behandelten RRMS-Patienten in beiden Zulassungsstudien ähnlich niedrig $[33,34]$. Neben der entzündungshemmenden Wirkung unterstreicht die Hemmung des De-novo-Pyrimidin-Biosynthesewegs die antiviralen Eigenschaften, wie bereits bei verschiedenen DNA- und RNA-Viren gezeigt werden konnte [35, 
Hier steht eine Anzeige.

Springer 


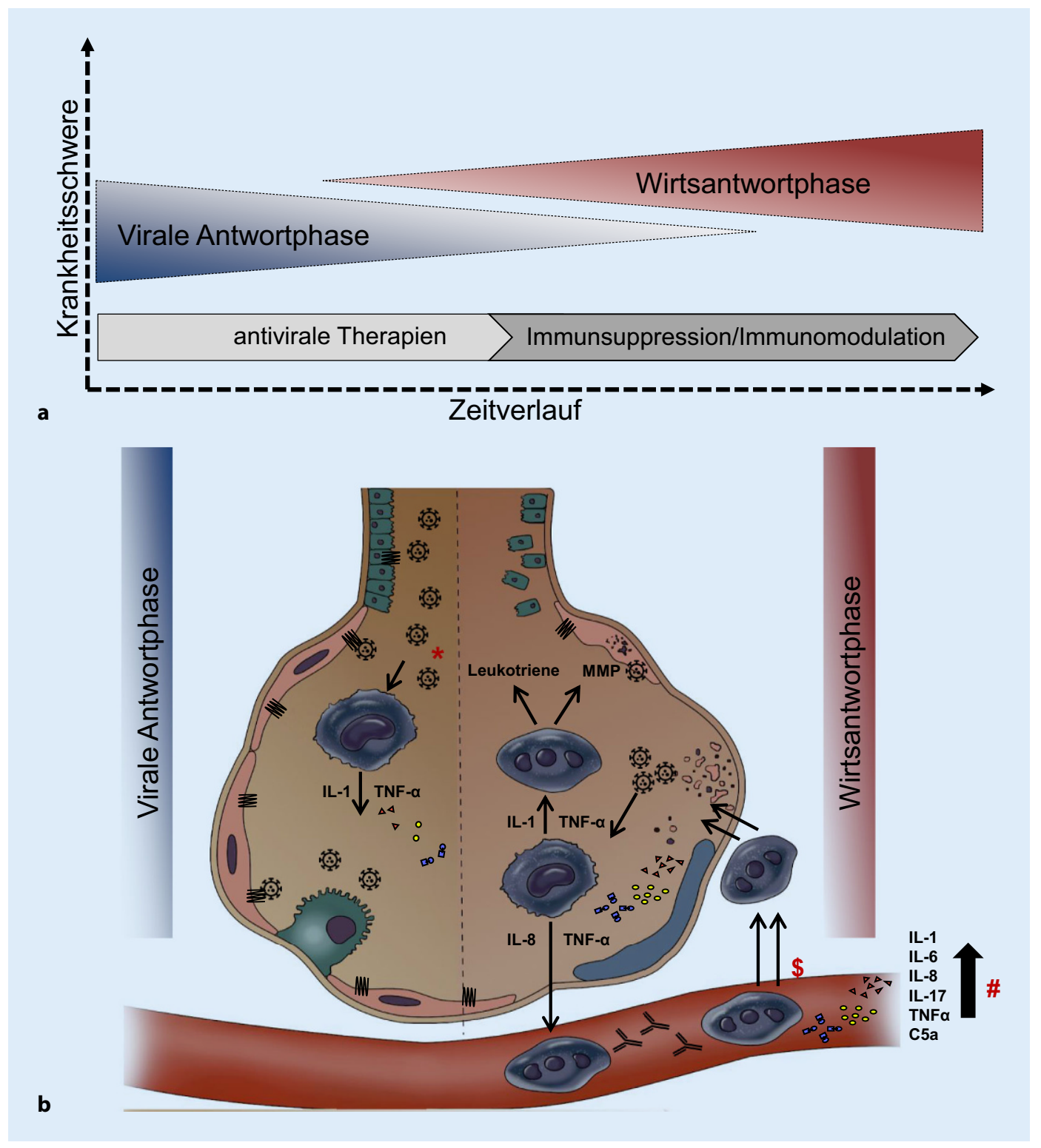

Abb. 1 Bedeutung der Inflammation während der Virus- und Wirtsantwortphase, $\mathbf{a}$ in frühen Stadien der COVID-19-Erkrankung können antivirale Behandlungsansätze wirksam sein, während in der Entzündungsphase immunsuppressive/-modulierende Therapien eine Option darstellen, $\mathbf{b}$ Betroffene Alveole während beider Phasen von COVID-19, links Immunmechanismen während der Virusantwortphase, rechts mehrere immunvermittelte Mechanismen bei akutem Lungenschaden während des entzündlichen Wirtsstadiums; Asterisk potenzielle Ziele von Immuntherapien mit antiviralem Potenzial; \$ Sequestrierung von Leukozyten als potenzielles Ziel; Raute Hemmung der Zytokinproduktion und -freisetzung während der Phase des Zytokinsturms als Behandlungsziel, MMP Matrixmetalloproteinasen; TNF- $a$ Tumor-NekroseFaktor- $\alpha$; IL-1 Interleukin 1. (Adaptiert nach [169])

36]. Studien zu SARS-CoV-2 wurden unseres Wissens bislang noch nicht durchgeführt.

Mykophenolatmofetil (MMF) hemmt reversibel die Inosinmonophosphatdehydrogenase und die Synthese von Guaninmonophosphat, wodurch die De-novo-Purinsynthese gestört wird [37]. Dies führt zu einer Reduktion der Proliferationsrate von $\mathrm{T}$ - und B-Lymphozyten. Darüber hinaus reduziert MMF die Produktion von proinflammatorischen Zytokinen wie Interferon $\gamma$ (IFN- $\gamma$ ) und Tumor-Nekrose-Faktor- $\alpha$ (TNF- $\alpha$ ). Bisher wird MMF bei MG, IIM, PACNS und NMOSD erfolgreich eingesetzt [38-41]. Aufgrund seiner Wirkungsweise erhöht es jedoch die Infektionswahrscheinlichkeit; insbesondere eine Reaktivierung von latenten Viren ist beschrieben [38]. Interessanterweise zeigte die aktive Verbindung, Mykophenolsäure, in einer Vielzahl von In-vitro-Versuchen multiple antivirale Eigenschaften, einschließlich gegen MERS-CoV [42-45]. Erste tierexperimentelle Arbeiten mit MERS-CoV-infizierten Nagetieren zeigten jedoch eine erhöhte Viruslast mit schweren oder sogar tödlichen Krankheitsverläufen unter MMF-Therapie [46]. In einer Fallserie mit 8 mit MERS-CoV infizierten Patienten überlebten dagegen alle Patienten unter der Therapiekombination von MMF mit IFN- $\beta$ [47]. Auf der anderen Seite wurden schwer oder tödlich verlaufende MERS-CoV-Infektionen bei nierentransplantierten Patienten berichtet, die eine MMF-Erhaltungstherapie erhielten [48]. Eine hohe Mortalitätsrate in diesem Patientenkollektiv konnte auch für COVID-19 beobachtet werden [49]. Zusammenfassend lässt sich sagen, dass eine kontinuierliche MMF-Therapie das Infektionsrisiko erhöhen könnte, während die vermuteten antiviralen Eigenschaften als akuter Behandlungsansatz gegen COVID-19 vermutet, bisher jedoch nur unzureichend erforscht sind [50].

Cladribin ist ein synthetisches Purinanalogon, welches die DNA-Synthese und -Reparatur in Lymphozyten beeinflusst. Cladribin führt bis zu 4 Monate nach der Anwendung insbesondere $\mathrm{zu}$ einer Verminderung der zirkulierenden $\mathrm{CD}^{+}{ }^{+} \mathrm{T}$ Zellen und für einen kürzeren Zeitraum zu einer Verminderung 
von $\mathrm{CD}^{+}{ }^{-}-\mathrm{T}-$ Zellen, NK-Zellen sowie reifen und B-Gedächtniszellen [51]. Die daraus resultierende Lymphopenie sorgt für eine passager erhöhte Infektanfälligkeit, insbesondere für Virusinfektionen, und für eine Virusreaktivierung [52-54]. Bemerkenswert ist, dass die immunsuppressive Pulstherapie scheinbar nur zeitweise kurz nach der Verabreichung mit einem höheren Infektionsrisiko assoziiert ist und dennoch der krankheitsmodifizierende Effekt bestehen bleibt.

\section{Immunzelldepletion durch Pulstherapien}

Ebenso wie Cladribin sorgen auch Therapieansätze mit monoklonalen Antikörpern (mAb) für eine passagere Zelldepletion. Insbesondere $\mathrm{mAb}$, die gegen $\mathrm{B}$-Zellen gerichtet sind, werden häufig bei neuroinflammatorischen Erkrankungen eingesetzt. Beispielsweise konnten mit Rituximab, einem chimären Anti-CD20-mAb, vielversprechende Ergebnisse bei einem breiten Spektrum entzündlicher neurologischer Erkrankungen, darunter der MG, der NMOSD, der Autoimmunenzephalitis, den entzündliche Neuropathien sowie der RRMS, erzielt werden [55]. Für die RRMS und die primär progrediente MS erhielt der humanisierte Anti-CD20-mAb Ocrelizumab 2018 die Zulassung $[56,57]$. Das CD20-Molekül wird während der gesamten B-Zell-Reifung exprimiert, frühe Pro-B-Zellen, Plasmazellen oder Plasmablasten tragen jedoch nicht das CD20-Antigen. Darüber hinaus wird dieses Antigen auch von einigen $\mathrm{CD}^{+}{ }^{-}$ T-Zellen exprimiert [58].

Inebilizumab ist ein $\mathrm{mAb}$ gegen das CD19-Antigen und zeigte positive Effekte bei NMOSD-Patienten [59]. Im Vergleich zu CD20-mAb ist unter Inebilizumab mit einer weitreichenden B-Zell-Depletion zu rechnen, da die Expression von CD19 im Pro-B-Zell-Stadium beginnt und CD19 auf der Mehrheit der Plasmazellen in den sekundären lymphatischen Organen, auf allen Plasmazellen im peripheren Blut und auf mehr als der Hälfte der Plasmazellen im Knochenmark exprimiert wird [60-62]. Generell ist unter einer B-Zell-depletierenden Therapie mit einer leicht erhöhten Infekthäufigkeit für die oberen Atemwege $\mathrm{zu}$ rechnen, aber auch schwere Influenzaverläufe wurden berichtet $[56,57,59]$. Insbesondere die Affektion von $\mathrm{CD}_{20}{ }^{+}-\mathrm{CD} 4^{+}-\mathrm{T}-Z$ Zllen könnte die akute Abwehr gegen SARS-CoV-2 verringern [4, 63]. Hinsichtlich der wiederholten Anwendung von mAb gegen CD19- und CD20-Antigene scheint das langfristige Ausbleiben einer B-Zell-Immunantwort das Hauptproblem zu sein. Im Allgemeinen zeigen alle 3 Medikamente oft eine anhaltende B-Zell-Depletion, noch bevor die geplante erneute Anwendung erfolgt [64]. Trotz einer Erholung der Gesamtzahl der B-Zellen besteht das entsprechende B-ZellKompartiment dann jedoch größtenteils aus naiven B-Zellen, während B-Gedächtniszellen im peripheren Blut noch Jahre nach der letzten Therapie nahezu abwesend sind [65]. Der Mangel an B-Gedächtniszellen könnte in der Zukunft für COVID-19 relevant sein, da eine niedrige Impfansprechrate unter B-Zell-Therapien vorzuliegen scheint [66-68]. Eine Impfung vor Therapiebeginn zur Bildung von langlebigen Plasmazellen ist daher ratsam. Im Gegensatz dazu könnte Inebilizumab aufgrund der zu erwartenden relevanten Reduktion langlebiger Plasmazellen im peripheren Blut und Knochenmark mit einem höheren Infektionsrisiko einhergehen, auch wenn sich dies in der bisherigen Zulassungsstudie für NMOSD nicht zeigte [69]. Ein weiterer Risikofaktor für COVID-19 stellt vermutlich die behandlungsbedingte Neutropenie und Hypogammaglobulinämie unter langjähriger Therapie dar [70].

Alemtuzumab ist ein humanisierter Anti-CD52-mAb, der für die Therapie der aktiven RRMS zugelassen ist. Das CD52Antigen wird auf der Oberfläche von B- und T-Zellen stark exprimiert und ist teilweise auch auf Monozyten und Makrophagen zu finden. [71, 72]. Die schnelle und ausgeprägte Lymphopenie in den ersten Monaten nach der Gabe von Alemtuzumab führt zu einem passager erhöhten Infektionsrisiko [54, 73].

Die Repopulationsdynamik der initial depletierten Immunzellen ist dabei unterschiedlich ausgeprägt. Da die Erholung von T-Zellen langsamer ist als die Repopulation von B-Zellen, sind opportunistische Infektionen wie Herpesreaktivierungen am ehesten auf eine T-Zell-Reduktion zurückzuführen [74]. Pneumonien und Infektionen der oberen Atemwege im Verlauf könnten jedoch mit der zusätzlich dokumentierten Hypogammaglobulinämie trotz der bereits ersichtlichen T- und B-ZellErholung zusammenhängen [72]. Interessant ist, dass nach der kritischen Phase der Alemtuzumab-induzierten Lymphopenie, ähnlich wie nach Cladribin, meist sowohl eine ausreichende Immunkompetenz als auch eine entsprechende Krankheitsstabilisierung erzielt werden kann [51]. Darüber hinaus bieten die Pulstherapien u. U. die Möglichkeit, weitere Therapiezyklen ohne erkennbare Auswirkungen auf die Wirksamkeit zu verzögern [54].

\section{Sequestrierung von Leukozyten in der Peripherie}

Natalizumab ist ein rekombinanter humanisierter $\mathrm{mAb}$, der gegen das Alpha-4-Integrin-Molekül auf Leukozyten gerichtet ist und die Transmigration peripherer Immunzellen in das zentrale Nervensystem blockiert $[75,76]$. Natalizumab wird derzeit erfolgreich für die Behandlung der RRMS eingesetzt. Schwere Atemwegserkrankungen werden aufgrund des Wirkmechanismus eher selten berichtet $[77,78]$.

Alpha-4-Integrin dient jedoch auch als Retentionssignal für lymphoide Vorläuferzellen im Knochenmark. So führt die Behandlung mit Natalizumab zu einer Vermehrung von NK-Zellen, T-Lymphozyten und v. a. B-Zellen im peripheren Blut [79-81]. Darüber hinaus wurde eine Zunahme von proinflammatorischen Zytokinen wie IL-2 und TNF- $\alpha$ beobachtet [82]. Bei entzündlichen Lungenerkrankungen konnte eine verminderte Migration in das Gewebe von Lymphozyten nach Blockierung von Alpha-4-Integrin gezeigt werden, was auf einen möglichen protektiven Effekt von Natalizumab bei SARS-CoV2-Infektionen hindeuten könnte [83].

Orale Sphingosin-1-Phosphat-Rezeptor-Modulatoren (S1PR-Modulatoren) sorgen für eine Sequestrierung von Leukozyten in sekundär lymphatischen Organen. Fingolimod und Ozanimod werden zur Behandlung der RRMS angewendet, während Siponimod kürzlich durch die europäische Arzneimittelagentur für die sekundär progrediente MS zugelassen wurde. S1PR-Modulatoren können zu einer Lymphozytenreduktion von bis zu 20-30\% führen, in einigen Fällen sogar bis zu einer Lymphopenie Grad IV [84-86]. Obwohl im klinischen Alltag teilweise eine pulmonale Verschlechterung unter Fingolimod seitens der Patienten berichtet wird, konnten in tierexperimentellen Arbeiten protektive Effekte bei Asthma gezeigt werden. Auch führte Fingolimod zu einer Reduktion der pulmonalen Gefäßleckage in murinen Modellen eines 
akuten Lungenschadens [87-91]. Darüber hinaus unterdrückt Fingolimod die IL-6- und IL-8-mRNA-Expression und Proteinsekretion aus Lungenepithelzellen und wird dahingehend in einer aktuellen Studie zur Behandlung von COVID-19 getestet (NCT04280588; [92]).

\section{Pleiotrope Immunmodulation}

Glatiramerazetat ist ein synthetisch hergestelltes Polypeptid, das aus 4 Aminosäuren besteht und mit Myelinantigenen um die T-Zell-Präsentation konkurriert. Bei RRMS-Patienten wird kein erhöhtes Infektionsrisiko unter Glatiramerazetat beobachtet [54].

Dimethylfumarat ist ebenfalls für die RRMS zugelassen. Die Wirkungsweise ist weiterhin nicht vollständig geklärt, umfasst aber entzündungshemmende und zytoprotektive Effekte. Dimethylfumarat kann zu einer ausgeprägten Lymphopenie führen, die mehrere Monate andauern kann [93]. Insbesondere Patienten über 55 Jahre haben ein erhöhtes Risiko für eine ausgeprägte Lymphopenie und damit für opportunistische Infektionen $[93,94]$.

\section{Zytokine oder Zytokinhemmer als Immuntherapie}

IFN- $\beta$ ist seit mehr als 20 Jahren für RRMS und die sekundär progrediente MS zugelassen [95]. Es verschiebt dabei die Zytokinproduktion zugunsten entzündungshemmender Zytokine und moduliert die Entzündungskaskaden von dendritischen sowie B-Zellen [54, 95-98].

Unter IFN- $\beta$-Therapie ist mit keinem erhöhten Infektionsrisiko zu rechnen. Nur wenige Patienten zeigen eine latente Leuko- oder Lymphopenie [54].

IFN- $\beta$ wird von Fibroblasten sezerniert und bindet an den IFN-Rezeptor, der intrazelluläre Signalkaskaden aktiviert, was u. a. zu einer erhöhten Genexpression von antiviralen und antiproliferativen Molekülen führt. Während einer Virusinfektion wird die ausgedehnte Freisetzung von IFN durch Zellen des angeborenen Immunsystems getriggert [99]. IFN- $\beta$ scheint dabei die größte antivirale Potenz unter den IFN zu besitzen und zeigte erste positive Signale in einer Phase-2-Studie bei COVID-19 in Kombination mit Lopinavir und Ritonavir [43, 100].

Die Hemmung von IL-6 ist ein neuerer Behandlungsansatz für entzündliche Erkrankungen aus dem rheumatologischen, aber auch neurologischen Formenkreis. Tocilizumab und Satralizumab sind $\mathrm{mAb}$ gegen den IL-6-Rezeptor und werden derzeit bei der NMOSD angewendet [101, 102]. IL-6 wird unmittelbar als Reaktion auf Infektionen produziert, aber ist auch bei chronischen Autoimmunprozessen hochreguliert [103]. Insbesondere spielt IL-6 eine Schlüsselrolle beim Zytokinfreisetzungssyndrom (CRS), welches bei Infektionen oder nach adaptiver T-Zell-Therapie auftreten kann [104-106]. Erhöhte Konzentrationen von IL-6 im Blut gehen meist mit einer schlechteren Prognose bei viralen Infektionen einher [107-109]. In Bezug auf COVID-19 wurden CRS häufig bei schweren und tödlichen Krankheitsfällen mit entsprechend hohen IL-6-Spiegeln im Blut berichtet [12, 110-112]. Tocilizumab ist bereits für die Behandlung eines durch chimäre Antigenrezeptor-T-Zellen induzierten CRS zugelassen [113]. Auch hinsichtlich COVID19 mit schweren CRS-Verläufen deuten verschiedene Berichte auf einen günstigen Krankheitsverlauf unter der Behandlung mit Tocilizumab hin [114-116]. In einer nichtrandomisierten, offenen, klinischen Studie erhielten 21 Patienten mit schwerem COVID-19 zusätzlich zu Lopinavir und Methylprednisolon auch Tocilizumab. Alle Patienten überlebten ohne relevante Nebenwirkungen [117]. Erste prospektive Studien untermauern diese Beobachtungen [118]. Weitere Studien wurden bereits initiiert (ChiCTR2000030894, NCT04310228, NCT04317092).

\section{Komplementinhibition}

Eculizumab ist ein humanisiertes $\mathrm{mAb}$, welcher die Spaltung und Aktivität des Komplementfaktors 5 (C5) blockiert und damit letztlich die komplementvermittelte Zelllyse hemmt. Eculizumab wurde als erster mAb für die Aquaporin-4-Antikörper-positive NMOSD und die therapierefraktäre MG zugelassen $[119,120]$. Eculizumab geht mit einem erhöhten Risiko von Pneumokokken- und Meningokokkeninfektionen einher, aber es liegen auch Berichte über Virusinfektionen vor, möglicherweise aufgrund der komplementabhängigen Regulation der T-Zell-Aktivierung [121-123]. Obwohl das Komplementsystem eine entscheidende Rolle bei der antiviralen Reaktion des Wirts spielt, wirft die erhöhte Komplementaktivierung während der Entzündungsphase bei COVID-19 ein neues Licht auf das mögliche destruktive Potenzial [121, 124]. Bei SARS-CoVinfizierten Mäusen scheint beispielsweise das Komplementsystem keine Schlüsselrolle bei der Kontrolle der Virusvermehrung zu spielen, sondern vermittelt eher Lungengewebsschäden durch die Hochregulation entzündlicher Zytokine und eine vermehrte Aktivierung neutrophiler Granulozyten [125]. Interessanterweise wurde die C3a- und C5a-Blockade als Behandlungsoption bei virusinduzierten akuten Lungenschäden angewendet. Eine gegen C5a gerichtete Antikörpertherapie konnte ebenfalls schwere Lungengewebsschäden bei MERS-CoV-infizierten Mäusen verhindern [124, 126]. Eine entsprechende klinische Studie für die Anwendung von Eculizumab in COVID19 wurde bereits initiiert (NCT04288713).

\section{Blockade intrazellulärer Signalwege}

Ciclosporin A (CsA) ist ein Immunsuppressivum, welches bei therapierefraktären MG- und IIM-Fällen eingesetzt wird [127, 128]. Eine CsA-Therapie scheint Patienten mit neuroinflammatorischen Erkrankungen nicht wesentlich anfälliger für Infektionen zu machen [129]. CsA bindet an zelluläre Zyklophiline zur Hemmung von Kalzineurin. Die Kalzineurinhemmung führt im Weiteren zu einer Reduktion der Transkription von proinflammatorischen Genen, die beispielsweise IL-2 kodieren. In-vitro-Studien konnten zeigen, dass CsA die Replikation verschiedener CoV hemmt $[18,100]$. Die geringe therapeutischen Breite von CsA scheint jedoch einen Einsatz bei mit CoV infizierten Patienten zu limitieren [130, 131].

\section{Akuttherapien}

Glukokortikosteroide (GKS) werden bei neuroinflammatorischen Erkrankungen breit angewendet und umfassen die i.v. Pulstherapie bei akuten Exazerbationen, aber auch kontinuierlich niedrigdosierte Therapieregime.

GKS schränken die Produktion zahlreicher Entzündungsmediatoren ein und hemmen die Migration von Immunzellen über die Blut-Hirn-Schranke [132].

Die Langzeitanwendung von GKS ist jedoch mit einer erhöhten Rate von bakteriellen und viralen Infektionen assoziiert 
[133]. Im Gegensatz zur kontinuierlichen Behandlung erhöht die wiederholte Pulstherapie zwar nicht das Risiko bakterieller Infektionen, es wurden jedoch vereinzelt schwere Virusinfektionen berichtet [134]. In Bezug auf COVID-19 gibt es derzeit eine Kontroverse über die Anwendung bei ARDS, da u. a. eine erhöhte Mortalität und Sekundärinfektionsraten bei CoV-Patienten auffielen, welche dem vermuteten regulierenden Effekt auf ein CRS gegenüberstehen [135-138]. Eine entsprechende prospektive Studie wurde initiiert (NCT04273321).

Intravenöse Immunglobuline (IVIG) werden hauptsächlich bei entzündlichen Neuropathien oder zur Behandlung der MG angewendet [139]. Neben ihrer günstigen Rolle bei der Erkennung und Abwehr von Krankheitserregern bei immundefizienten Patienten könnten IVIG auch Effekte auf die durch Krankheitserreger verursachte Wirtsinflammation haben. Was die Aktivierung myeloischer Zellen in der Entzündungsphase betrifft, so sättigen IVIG die IgG-Recycling-Kapazität und reduzieren folglich die Konzentrationen an neutralisierenden Antikörpern, die für die Aktivierung von Makrophagen und NKZellen verantwortlich sind $[140,141]$. Darüber hinaus hemmen IVIG sowohl die TNF- $\alpha$-induzierte NF- $\kappa B$-Aktivierung bei Neutrophilen als auch die Produktion proinflammatorischer Zytokine [142-145]. Da auch eine dysregulierte exzessive Komplementaktivität ein Bestandteil der überschießenden Entzündungsphase ist, könnte eine IVIG-vermittelte Neutralisierung der Komplementfaktoren von Vorteil sein [146, 147]. IVIG zeigen auch indirekt protektive Effekte hinsichtlich der Migration von Entzündungszellen [143, 148]. Zusammengefasst könnten sich diese Effekte als nützlich erweisen, um den Schweregrad der Erkrankung zu mildern oder möglicherweise den Ausbruch eines akuten entzündlichen Lungenschadens zu verhindern. Bisher wurden IVIG meist in Kombination mit weiteren Immuntherapien im Falle einer SARS-CoV-2-Infektion angewendet, sodass bisher keine eindeutigen Rückschlüsse hinsichtlich der Wirksamkeit gezogen werden können. Frühere Studien an septischen Patienten zeigten jedoch ein günstiges Ergebnis nach IVIG-Gabe, und erste klinische Studien wurden bereits initiiert (NCT04261426; [149]).

Apheresebehandlungen gelten insbesondere bei schweren schubartigen Verschlechterungen als effektive Therapieoption [150]. Höhere Infektionsraten werden zwar während und nach den Behandlungszyklen beobachtet, umfassen aber hauptsächlich katheterassoziierte Infektionen. Im Hinblick auf die entzündliche Wirtsphase könnte die Entfernung zirkulierender entzündlicher Zytokine einen entsprechenden Vorteil bewirken [151]. Aufgrund der geringen Zahl randomisierter Studien bei septischen Patienten gibt es jedoch keine ausreichende Evidenz für ein Plasmaaustauschverfahren bei COVID-19 [152].

\section{Implikationen für die Anwendung von \\ Immuntherapien im Zeitalter von COVID-19}

Seit Jahrzehnten stellt die klassische Immunsuppression die therapeutische Grundlage bei neuroinflammatorischen Erkrankungen dar. Während in der Vergangenheit viele Behandlungsstrategien auf dem Gebiet der Neurologie mangels Alternativen aus anderen Krankheitsfeldern übernommen wurden, hat sich das Repertoire an selektiven Immuntherapien zuletzt merklich erweitert $[153,154]$. Insbesondere für die Behandlung der MS steht eine Vielzahl selektiv wirkender Substanzen zur Verfü- gung. Aufgrund der nur kurzen Anwendungszeit neuer Immuntherapien beruht die Erfahrung hinsichtlich des Infektionsrisikos oder des Impfansprechens bisher jedoch nur auf wenigen Daten aus dem klinischen Alltag.

Angesichts der aktuellen COVID-2019-Pandemie wird ein anhaltend hohes Infektionsrisiko für immunsupprimierte Patienten angenommen, sodass eine Unsicherheit sowohl bei den Patienten als auch den Behandlern besteht.

Anhand der bisherigen Erfahrungen mit Immuntherapien und deren Wirkungsweise kann man jedoch festhalten, dass bei einem Großteil der angewendeten Immuntherapien eine Therapieinitiierung bzw. -fortsetzung wahrscheinlich mit nur einem gering erhöhten Infektionsrisiko einhergeht [155]. Dennoch sollten Aspekte wie Krankheitsaktivität, bisheriger Therapieverlauf, Patientenalter, Morbidität und mögliche Therapiealternativen in die Bewertung mit einfließen. Insbesondere der GKS-sparende Effekt einiger Immuntherapien sollte nicht unberücksichtigt bleiben.

Bei langjährigen milden oder stabilen Krankheitsverläufen unter klassischen Immunsuppressiva sollten eine Dosisreduktion oder Deeskalationsstrategien evaluiert werden. Bei Abwesenheit einer klinischen oder paraklinischen Aktivität bei chronisch progredienten MS-Verläufen sollte der Einsatz von Mitoxantron vorerst nicht erfolgen. Auf der anderen Seite kann v. a. bei PACNS-Patienten das Absetzen der Therapie zu irreversiblen Krankheitsschüben führen. Für die Behandlung von RRMS-Patienten sind die Therapien für den milden Krankheitsverlauf mit keinem oder nur einem geringen Risiko verbunden. Aber auch intensivierte Therapieregime mit S1PR-Modulatoren oder Natalizumab sind mit einem nur leicht erhöhten Risiko für Virusinfektionen verbunden und sollten fortgesetzt werden, wenngleich für Natalizumab auch eine Verlängerung des Therapieintervalls zu evaluieren ist [156].

Pulstherapien, einschließlich mAb gegen CD19/20 sowie CD52 und Cladribin, sind über einen begrenzten Zeitraum mit einem erhöhten Infektionsrisiko verbunden. Das Ausmaß der Immunsuppression und die Repopulationsdynamik von Immunzellen unterscheiden sich jedoch grundlegend zwischen solchen Therapeutika und sollten bei Behandlungsentscheidungen berücksichtigt werden. Insbesondere nach der B-ZellDepletion durch Rituximab, Ocrelizumab oder Inebilizumab entwickelt sich in den nächsten 6-12 Monaten eine reduzierte humorale Immunität, die durch die anschließende Zyklusgabe aufrechterhalten wird. Daher scheint es bei wiederholter Anwendung ratsam, serologische Marker wie den CD19-B-ZellStatus zu berücksichtigen, um langfristige Nebenwirkungen wie eine Hypogammaglobulinämie zu vermeiden [70, 157].

Hinsichtlich der Wirkungsweise von Cladribin und Alemtuzumab ist 6-12 Monate nach der Applikation mit einer Normalisierung der Gesamtlymphozytenzahl durch die Immunrekonstitution zu rechnen. Es kann erwogen werden, eine erneute Zyklusgabe von Cladribin oder Alemtuzumab bei fehlenden klinischen oder paraklinischen Krankheitshinweisen hinauszuzögern.

Für Eculizumab gibt es derzeit keine Hinweise auf eine erhöhte Anfälligkeit für eine SARS-CoV-2-Infektion. In Anbetracht der Indikation für die therapierefraktäre MG und die schubförmige NMOSD sollte die Therapie daher fortgesetzt 
Tab. 1 Übersicht über die häufigsten Immuntherapien bei neuroimmunologischen Erkrankungen und ein entsprechender Diskussionsvorschlag hinsichtlich deren Anwendung in Zeiten von COVID 19

\begin{tabular}{|c|c|c|c|}
\hline Substanzen & Indikationen & Therapiestrategien in Zeiten von COVID-19 & $\begin{array}{l}\text { Therapiestrategien im Falle } \\
\text { einer SARS-CoV-2-Infektion }\end{array}$ \\
\hline \multicolumn{4}{|c|}{ Interferenz mit der DNA-Synthese } \\
\hline Azathioprin & $\begin{array}{l}\text { MG, NMOSD, PACNS, IIM, AIE, sekundäre } \\
\text { ZNS-Vaskulitiden/Kollagenosen, Neurosar- } \\
\text { koidose }\end{array}$ & $\begin{array}{l}\text { Fortsetzung; bei langjährigem stabilem Krank- } \\
\text { heitsverlauf Dosisreduktion }\end{array}$ & Pausieren \\
\hline Methotrexat & $\begin{array}{l}\text { MG, NMOSD, PACNS, IIM, AIE, sekundäre } \\
\text { ZNS-Vaskulitiden/Kollagenosen, Neurosar- } \\
\text { koidose }\end{array}$ & $\begin{array}{l}\text { Fortsetzung; bei langjährigem stabilem Krank- } \\
\text { heitsverlauf Dosisreduktion }\end{array}$ & Pausieren \\
\hline Cyclophosphamid & $\begin{array}{l}\text { PACNS, AIE, sekundäre ZNS-Vaskulitiden/ } \\
\text { Kollagenosen }\end{array}$ & $\begin{array}{l}\text { Fortsetzung; bei langjährigem stabilem Krank- } \\
\text { heitsverlauf Deeskalationstherapien }\end{array}$ & Pausieren \\
\hline Mitoxantron & SPMS, NMOSD & $\begin{array}{l}\text { Therapiealternativen; bei langjährigem stabilem } \\
\text { Krankheitsverlauf Dosisreduktion oder Absetzen }\end{array}$ & Pausieren \\
\hline Teriflunomid & RRMS & Fortsetzung & $\begin{array}{l}\text { Fortsetzung; bei ausgepräg- } \\
\text { ter Lymphopenie pausieren }\end{array}$ \\
\hline $\begin{array}{l}\text { Mykophenolatmo- } \\
\text { fetil }\end{array}$ & $\begin{array}{l}\text { MG, NMOSD, PACNS, IIM, sekundäre ZNS-Vas- } \\
\text { kulitiden/Kollagenosen, Neurosarkoidose }\end{array}$ & Fortsetzung & $\begin{array}{l}\text { Fortsetzung; bei ausgepräg- } \\
\text { ter Lymphopenie pausieren }\end{array}$ \\
\hline Cladribin & RRMS & Zyklus bei Krankheitsstabilität verzögern & $\begin{array}{l}\text { Pausieren; Therapiealternati- } \\
\text { ven }\end{array}$ \\
\hline \multicolumn{4}{|c|}{ Immunzelldepletion durch Pulstherapien } \\
\hline Rituximab & $\begin{array}{l}\text { MG, NMOSD, PACNS, IIM, AIE, sekundäre } \\
\text { ZNS-Vaskulitiden/Kollagenosen, CIDP }\end{array}$ & $\begin{array}{l}\text { Zyklus bei Krankheitsstabilität verzögern; } \\
\text { CD19-B-Zell-Monitoring }\end{array}$ & $\begin{array}{l}\text { Pausieren; Therapiealternati- } \\
\text { ven }\end{array}$ \\
\hline Ocrelizumab & RRMS, PPMS & $\begin{array}{l}\text { Zyklus bei Krankheitsstabilität verzögern, insbe- } \\
\text { sondere bei PPMS; CD19-B-Zell-Monitoring }\end{array}$ & $\begin{array}{l}\text { Pausieren; Therapiealternati- } \\
\text { ven }\end{array}$ \\
\hline Inebilizumab & NMOSD & $\begin{array}{l}\text { Zyklus bei Krankheitsstabilität verzögern; } \\
\text { CD19-B-Zell-Monitoring }\end{array}$ & $\begin{array}{l}\text { Pausieren; Therapiealternati- } \\
\text { ven }\end{array}$ \\
\hline Alemtuzumab & RRMS & $\begin{array}{l}\text { Zyklus bei Krankheitsstabilität verzögern; Thera- } \\
\text { piealternativen }\end{array}$ & $\begin{array}{l}\text { Pausieren; Therapiealternati- } \\
\text { ven }\end{array}$ \\
\hline \multicolumn{4}{|c|}{ Sequestrierung von Leukozyten in der Peripherie } \\
\hline $\begin{array}{l}\text { Fingolimod/ } \\
\text { Ozanimod }\end{array}$ & RRMS & Fortsetzung & $\begin{array}{l}\text { Fortsetzung, ggf. Pausieren } \\
\text { für wenige Wochen }\end{array}$ \\
\hline Siponimod & SPMS & Fortsetzung & $\begin{array}{l}\text { Fortsetzung, Pausieren je- } \\
\text { doch vertretbar }\end{array}$ \\
\hline Natalizumab & RRMS & Fortsetzung, ggf. Zyklusverlängerung & $\begin{array}{l}\text { Fortsetzung, ggf. Zyklusver- } \\
\text { längerung }\end{array}$ \\
\hline \multicolumn{4}{|c|}{ Pleiotrope Immunmodulation } \\
\hline Glatiramerazetat & RRMS & Fortsetzung & Fortsetzung \\
\hline Dimethylfumarat & RRMS & $\begin{array}{l}\text { Fortsetzung; Pausieren bei ausgeprägter Lym- } \\
\text { phopenie }\end{array}$ & $\begin{array}{l}\text { Fortsetzung; Pausieren bei } \\
\text { ausgeprägter Lymphopenie }\end{array}$ \\
\hline \multicolumn{4}{|c|}{ Zytokine als Immuntherapie } \\
\hline IFN- $\beta$ & RRMS, SPMS & Fortsetzung & Fortsetzung \\
\hline $\begin{array}{l}\text { Tocilizumab/ } \\
\text { Satralizumab }\end{array}$ & NMOSD & Fortsetzung & Fortsetzung \\
\hline \multicolumn{4}{|c|}{ Komplementinhibition } \\
\hline Eculizumab & MG, NMOSD & Fortsetzung & Fortsetzung \\
\hline \multicolumn{4}{|c|}{ Blockade intrazellulärer Signalwege } \\
\hline Ciclosporin A & MG, IIM & Fortsetzung & $\begin{array}{l}\text { Fortsetzung, ggf. Dosisreduk- } \\
\text { tion }\end{array}$ \\
\hline
\end{tabular}

werden. Dasselbe gilt für die Anwendung von mAb gegen IL-6 bei Patienten mit einer NMOSD.

IVIG und Plasmaaustauschverfahren haben nur minimale Auswirkungen auf die Immunantwort des Wirts, und es gibt derzeit keine Hinweise darauf, dass beide Interventionen ein zusätzliches Risiko für eine SARS-CoV-2-Infektion darstellen.
Intravenöse GKS-Pulstherapien hingegen sollten nur bei klinisch manifester Verschlechterung Anwendung finden. Hinsichtlich der oralen GKS-Therapie sollte, wie sonst auch, eine so niedrige Tagesdosis wie möglich gewählt werden. Tab. 1 enthält eine Übersicht über die aktuell angewandten Immuntherapien und entsprechende Empfehlungen seitens der Autoren in 
Tab. 1 (Fortsetzung)

\begin{tabular}{|c|c|c|c|}
\hline Substanzen & Indikationen & Therapiestrategien in Zeiten von COVID-19 & $\begin{array}{l}\text { Therapiestrategien im Falle } \\
\text { einer SARS-CoV-2-Infektion }\end{array}$ \\
\hline \multicolumn{4}{|l|}{ Akuttherapien } \\
\hline GKS-Pulstherapie & $\begin{array}{l}\text { MS, MG, NMOSD, PACNS, IIM, AIE, sekundäre } \\
\text { ZNS-Vaskulitiden/Kollagenosen, Neurosarkoi- } \\
\text { dose }\end{array}$ & Nur bei akuter Krankheitsaktivität & Pausieren, Dosisreduktion \\
\hline $\begin{array}{l}\text { GKS-Dauer- } \\
\text { therapie/"tapering" }\end{array}$ & $\begin{array}{l}\text { NMOSD, MG, PACNS, IIM, CIDP, sekundäre } \\
\text { ZNS-Vaskulitiden/Kollagenosen, Neurosarkoi- } \\
\text { dose }\end{array}$ & Bei Krankheitsstabilität Dosisreduktion erwägen & $\begin{array}{l}\text { Bei Krankheitsstabilität Dosis- } \\
\text { reduktion erwägen }\end{array}$ \\
\hline$I V I G$ & MG, IIM, CIDP, GBS & Fortsetzung, ggf. Zyklusverlängerung & $\begin{array}{l}\text { Fortsetzung, ggf. Zyklusver- } \\
\text { längerung }\end{array}$ \\
\hline $\begin{array}{l}\text { Plasmapherese/ } \\
\text { Immunadsorption }\end{array}$ & MS, MG, NMOSD, AIE, IIM, GBS & Fortsetzung & $\begin{array}{l}\text { Fortsetzung bei entsprechen- } \\
\text { der Indikation }\end{array}$ \\
\hline
\end{tabular}

AIE Autoimmunenzephalitis, GBS Guillain-Barré-Syndrom, GKS Glukokortikosteroide, CIDP Chronisch inflammatorische demyelinisierende Polyneuropathie, IFN- $\beta$ Interferon-beta, IIM idiopathisch inflammatorische Myopathie, IVIG i.v. Immunglobuline, MG Myasthenia gravis, MS Multiple Sklerose, NMOSD Neuromyelitis-optica-Spektrumserkrankungen, PACNS primäre Angiitis des zentralen Nervensystems, PPMS primär chronisch progrediente Multiple Sklerose, RRMS schubförmig remittierende Multiple Sklerose, SPMS sekundär chronisch progrediente Multiple Sklerose

Zeiten der SARS-CoV-2-Epidemie und im Falle einer akuten Infektion.

\section{Implikationen für Impfungen unter Immuntherapien im Zeitalter von COVID-19}

Im Hinblick auf die intensive Suche nach Impfstoffen stellt sich die Frage, inwieweit bei Patienten unter jeweiliger Immuntherapie eine adäquate Impfreaktion zu erwarten ist. Leider liefern die wenigen vorhandenen Studien widersprüchliche Ergebnisse $[66,158-162]$. Während eine ausreichende Impfantwort bei immunmodulatorischen und selektiven Behandlungsstrategien wahrscheinlich ist, scheinen klassische Immunsuppressiva und insbesondere B-Zell-depletierende Therapien in einer solchen Situation ungünstig zu sein $[67,68,158,159,163,164]$. Hierbei könnte jedoch die Immunrekonstitution nach gepulster Zelldepletion mit Alemtuzumab oder Cladribin ein entscheidender Vorteil für eine erfolgreiche und nebenwirkungsarme Impfung im Verlauf darstellen [165]. Auf der anderen Seite kann auch das Ausmaß der Immunantwort gegen den jeweiligen Impfstoff zu einer verstärkten Krankheitsaktivität nach der Impfung führen $[166,167]$. Weiterhin müssen die bisher geltenden Kontraindikationen von Impfstoffen mit abgeschwächten Lebendviren, insbesondere unter krankheitsmodifizierenden Therapien, berücksichtigt werden [168].

\section{Resümee}

Immuntherapien sind ein entscheidender Bestandteil der Behandlung neuroimmunologischer Erkrankungen. Aktuell ist jedoch ungeklärt, ob und wie diese Therapien das Risiko von COVID-19 und den mit dieser Erkrankung einhergehenden Komplikationen erhöhen. Das Risiko eines Behandlungsabbruchs ist nach aktuellem Stand jedoch als höher zu bewerten als das Risiko eines schweren COVID-19-Verlaufs unter laufender Immuntherapie.

Künftig muss das potenzielle, langfristige Infektionsrisiko bei Behandlungsentscheidungen stärker untersucht werden. Darüber hinaus sollten zugelassene selektive krankheitsmodifizierende Substanzen aus anderen Indikationen auch auf ihren Einsatz bei seltenen neuroinflammatorischen Erkrankungen getestet werden. Es ist daher höchste Zeit, die Off-Label-UseRegelungen auch unter dem Aspekt der potenziellen Infektionsrisiken zu erweitern bzw. zu lockern.

Einige Immuntherapien könnten auch hilfreich zur Behandlung von COVID-19-Fällen sein. Dies umfasst die antiviralen Eigenschaften von IFN- $\beta$, CsA und Teriflunomid, die Leukozytensequestrierung durch Natalizumab oder S1PR-Modulatoren, die Komplementhemmung durch Eculizumab sowie mögliche immunregulatorische Effekte im Falle eine Zytokinsturms durch IVIG oder GKS. Die größte Herausforderung der aktuellen und zukünftigen Anwendungen von Immuntherapien bei COVID-19 könnte jedoch darin bestehen, den richtigen Zeitpunkt für den Beginn der Behandlung zu bestimmen.

Literatur

1. Huang C, Wang Y, Li X et al (2020) Clinical features of patients infected with 2019 novel coronavirus in Wuhan, China. Lancet 395:497-506

2. COVID-19Map (2020) https://coronavirus.jhu.edu/map.html. Zugegriffen: 23. Apr. 2020

3. Novi G, Mikulska M, Briano F et al (2020) COVID-19 in a MS patient treated with ocrelizumab: does immunosuppression have a protective role? Mult Scler Relat Disord 42:102120

4. Baker D, Marta M, Pryce G et al (2017) Memory B cells are major targets for effective immunotherapy in relapsing multiple sclerosis. EBioMedicine 16:41-50

5. Gilhus NE, Romi F, Hong Y et al (2018) Myasthenia gravis and infectious disease. J Neurol 265:1251-1258

6. Winkelmann A, Loebermann M, Reisinger EC et al (2016) Disease-modifying therapies and infectious risks in multiple sclerosis. Nat Rev Neurol 12:217-233

7. Fung S-Y, Yuen K-S, Ye Z-W et al (2020) A tug-of-war between severe acute respiratory syndrome coronavirus 2 and host antiviral defence: lessons from other pathogenic viruses. Emerg Microbes Infect 9:558-570

8. Fu Y, Cheng Y, WU Y (2020) Understanding SARS-CoV-2-mediated inflammatory responses: from mechanisms to potential therapeutic tools. Virol Sin. https://doi. org/10.1007/s12250-020-00207-4

9. Ahmadpoor P, Rostaing L (2020) Why the immune system fails to mount an adaptive immune response to a Covid-19 infection. Transpl Int. https://doi.org/ 10.1111/TRI.13611

10. Teijaro JR, Walsh KB, Rice S et al (2014) Mapping the innate signaling cascade essential for cytokine storm during influenza virus infection. Proc Natl Acad Sci USA 111:3799-3804 
11. Takada A, Kawaoka Y (2003) Antibody-dependent enhancement of viral infection: molecular mechanisms and in vivo implications. Rev Med Virol 13:387-398

12. Mehta P, McAuley DF, Brown M et al (2020) COVID-19: consider cytokine storm syndromes and immunosuppression. Lancet 395:1033-1034

13. Bersanelli M (2020) Controversies about COVID-19 and anticancer treatment with immune checkpoint inhibitors. Immunotherapy. https://doi.org/10.2217/imt2020-0067

14. XU J, Zhao S, Teng Tet al (2020) Systematic comparison of two animal-to-human transmitted human Coronaviruses: SARS-coV-2 and SARS-coV. Viruses 12:244

15. Kalil AC (2020) Treating COVID-19-off-label drug use, compassionate use, and randomized clinical trials during pandemics. JAMA. https://doi.org/10.1001/ jama.2020.4742

16. Yuen K-S, Ye Z-W, Fung S-Y et al (2020) SARS-CoV-2 and COVID-19: The most important research questions. Cell Biosci 10:40

17. Gralinski LE, Sheahan TP, Morrison TE et al (2018) Complement activation contributes to severe acute respiratory syndrome Coronavirus pathogenesis. mBio. https://doi.org/10.1128/mBio.01753-18

18. de Wilde AH, Raj VS, Oudshoorn D et al (2013) MERS-coronavirus replication induces severe in vitro cytopathology and is strongly inhibited by cyclosporin A or interferon-a treatment. J Gen Virol 94:1749-1760

19. Enjuanes L, Zuñiga S, Castaño-Rodriguez Cet al (2016) Molecular basis of Coronavirus virulence and vaccine development. Adv Virus Res 96:245-286

20. Zhao Y, Zhao Z, Wang Y et al (2020) Single-cell RNA expression profiling of ACE2, the putative receptor of Wuhan 2019-nCov

21. Zou L, Ruan F, Huang M et al (2020) SARS-coV-2 viral load in upper respiratory specimens of infected patients. N Engl J Med 382:1177-1179

22. Zhu J, Mohan C (2010) Toll-like receptor signaling pathways--therapeutic opportunities. Mediators Inflamm 2010:781235

23. Bahl K, Kim S-K, Calcagno C et al (2006) IFN-induced attrition of CD8 T cells in the presence or absence of cognate antigen during the early stages of viral infections. $\mathrm{J}$ Immunol 176:4284-4295

24. Kindler E, Thiel V, Weber F (2016) Interaction of SARS and MERS Coronaviruses with the Antiviral interferon response. Adv Virus Res 96:219-243

25. Yoshikawa T, Hill T, Li Ket al (2009) Severe acute respiratory syndrome (SARS) coronavirus-induced lung epithelial cytokines exacerbate SARS pathogenesis by modulating intrinsic functions of monocyte-derived macrophages and dendritic cells. J Virol 83:3039-3048

26. Liu L, Wei Q, Lin Q et al (2019) Anti-spike IgG causes severe acute lung injury by skewing macrophage responses during acute SARS-CoV infection. JCI Insight. https://doi.org/10.1172/jci.insight. 123158

27. Stankiewicz JM, Kolb H, Karni A et al (2013) Role of immunosuppressive therapy for the treatment of multiple sclerosis. Neurotherapeutics 10:77-88

28. Hartung H-P, Gonsette R, Konig N et al (2002) Mitoxantrone in progressive multiple sclerosis: a placebo-controlled, double-blind, randomised, multicentre trial. Lancet 360:2018-2025

29. Danza A, Ruiz-Irastorza G (2013) Infection risk in systemic lupus erythematosus patients: susceptibility factors and preventive strategies. Lupus 22:1286-1294

30. McLean-Tooke A, Aldridge C, Waugh S et al (2009) Methotrexate, rheumatoid arthritis and infection risk: what is the evidence? Baillieres Clin Rheumatol 48:867-871

31. La Mantia L, Mascoli N, Milanese C (2007) Azathioprine. Safety profile in multiple sclerosis patients. Neurol Sci 28:299-303

32. Löffler M, Klein A, Hayek-Ouassini M et al (2004) Dihydroorotate dehydrogenase mRNA and protein expression analysis in normal and drug-resistant cells. Nucleosides Nucleotides Nucleic Acids 23:1281-1285

33. O'Connor P, Wolinsky JS, Confavreux C et al (2011) Randomized trial of oral teriflunomide for relapsing multiple sclerosis. N Engl J Med 365:1293-1303

34. Confavreux C, O'Connor P, Comi G et al (2014) Oral teriflunomide for patients with relapsing multiple sclerosis (TOWER): a randomised, double-blind, placebocontrolled, phase 3 trial. Lancet Neurol 13:247-256

35. Bilger A, Plowshay J, Ma S et al (2017) Leflunomide/teriflunomide inhibit EpsteinBarr virus (EBV)- induced lymphoproliferative disease and lytic viral replication. Oncotarget 8:44266-44280
36. Xiong R, Zhang L, Li S et al (2020) Novel and potent inhibitors targeting DHODH, a rate-limiting enzyme in de novo pyrimidine biosynthesis, are broad-spectrum antiviral against RNA viruses including newly emerged coronavirus SARS-COV-2

37. Allison AC, Eugui EM (2000) Mycophenolate mofetil and its mechanisms of action. Immunopharmacology 47:85-118

38. Meriggioli MN, Ciafaloni E, Al-Hayk KA et al (2003) Mycophenolate mofetil for myasthenia gravis: an analysis of efficacy, safety, and tolerability. Neurology 61:1438-1440

39. Beuker C, Schmidt A, Strunk D et al (2018) Primary angiitis of the central nervous system: diagnosis and treatment. Ther Adv Neurol Disord 11:1756286418785071

40. Olivo Pallo PA, de Souza FHC, Miossi Ret al (2018) Mycophenolate mofetil in patients with refractory systemic autoimmune myopathies: case series. Adv Rheumatol 58:34

41. Montcuquet A, Collongues N, Papeix Cet al (2017) Effectiveness of mycophenolate mofetil as first-line therapy in AQP4-IgG, MOG-IgG, and seronegative neuromyelitis optica spectrum disorders. Mult Scler 23:1377-1384

42. Cheng K-W, Cheng S-C, Chen W-Y et al (2015) Thiopurine analogs and mycophenolic acid synergistically inhibit the papain-like protease of Middle East respiratory syndrome coronavirus. Antivir Res 115:9-16

43. Chan JFW, Chan K-H, Kao RYT et al (2013) Broad-spectrum antivirals for the emerging Middle East respiratory syndrome coronavirus. J Infect 67:606-616

44. Hart BJ, Dyall J, Postnikova E et al (2014) Interferon- $\beta$ and mycophenolic acid are potent inhibitors of Middle East respiratory syndrome coronavirus in cell-based assays. J Gen Virol 95:571-577

45. Shen L, Niu J, Wang C et al (2019) High-throughput screening and identification of potent broad-spectrum inhibitors of Coronaviruses. J Virol. https://doi.org/10. 1128/JVI.00023-19

46. Chan JF-W, Yao Y, Yeung M-L et al (2015) Treatment with Lopinavir/Ritonavir or interferon-B1b improves outcome of MERS-coV infection in a nonhuman primate model of common marmoset. J Infect Dis 212:1904-1913

47. Al Ghamdi M, Alghamdi KM, Ghandoora Y et al (2016) Treatment outcomes for patients with Middle Eastern Respiratory Syndrome Coronavirus (MERS CoV) infection at a coronavirus referral center in the Kingdom of Saudi Arabia. BMC Infect Dis 16:174

48. Faure E, Poissy J, Goffard A et al (2014) Distinct immune response in two MERSCoV-infected patients: can we go from bench to bedside? Plos One 9:e88716

49. Akalin E, Azzi Y, Bartash Ret al (2020) Covid-19 and kidney transplantation. NEngl J Med. https://doi.org/10.1056/NEJMc2011117

50. Zumla A, Chan JFW, Azhar El et al (2016) Coronaviruses - drug discovery and therapeutic options. Nat Rev Drug Discov 15:327-347

51. Sorensen PS, Sellebjerg F (2019) Pulsed immune reconstitution therapy in multiple sclerosis. Ther Adv Neurol Disord 12:1756286419836913

52. Giovannoni $G$, Soelberg Sorensen P, Cook Set al (2018) Safety and efficacy of cladribine tablets in patients with relapsing-remitting multiple sclerosis: Results from the randomized extension trial of the CLARITY study. Mult Scler 24:1594-1604

53. CookS, Vermersch P, Comi G et al (2011) Safety and tolerability of cladribine tablets in multiple sclerosis: the CLARITY (CLAdRIbine Tablets treating multiple sclerosis orallY) study. Mult Scler 17:578-593

54. Klotz L, Havla J, Schwab Net al (2019) Risks and risk management in modern multiple sclerosis immunotherapeutic treatment. Ther Adv Neurol Disord 12:1756286419836571

55. Whittam DH, Tallantyre EC, Jolles S et al (2019) Rituximab in neurological disease: principles, evidence and practice. Pract Neurol 19:5-20

56. Hauser SL, Bar-Or A, Comi G et al (2017) Ocrelizumab versus interferon beta-1a in relapsing multiple sclerosis. N Engl J Med 376:221-234

57. Montalban X, Hauser SL, Kappos L et al (2017) Ocrelizumab versus placebo in primary progressive multiple sclerosis. N Engl I Med 376:209-220

58. Schuh E, Berer K, Mulazzani Met al (1950) Features of human CD3+CD20+ T cells. JImmunol 197:1111-1117

59. Cree BAC, Bennett JL, Kim HJ et al (2019) Inebilizumab for the treatment of neuromyelitis optica spectrum disorder (N-MOmentum): a double-blind, randomised placebo-controlled phase 2/3 trial. Lancet 394:1352-1363 
60. Halliley JL, Tipton CM, Liesveld J et al (2015) Long-lived plasma cells are contained within the CD19(-)CD38(hi)CD138(+) subset in human bone marrow. Immunity 43:132-145

61. Mei HE, Wirries I, Frölich D et al (2015) A unique population of IgG-expressing plasma cells lacking CD19 is enriched in human bone marrow. Blood 125:1739-1748

62. Chen D, Gallagher S, Monson NL et al (2016) Inebilizumab, a B cell-depleting antiCD19 antibody for the treatment of autoimmune neurological diseases: insights from preclinical studies. JCM 5:107

63. Misumi I, Whitmire JK (2014) B cell depletion curtails CD4+ T cell memory and reduces protection against disseminating virus infection. I Immunol 192:1597-1608

64. Palanichamy A, Jahn S, Nickles D et al (2014) Rituximab efficiently depletes increased CD20-expressing T cells in multiple sclerosis patients. J Immunol 193:580-586

65. Sutter JA, Kwan-Morley J, Dunham J et al (2008) A longitudinal analysis of SLE patients treated with rituximab (anti-CD20): factors associated with B lymphocyte recovery. Clin Immunol 126:282-290

66. Kim W, Kim S-H, Huh S-Y et al (2013) Reduced antibody formation after influenza vaccination in patients with neuromyelitis optica spectrum disorder treated with rituximab. Eur J Neurol 20:975-980

67. van Assen S, Holvast A, Benne CA et al (2010) Humoral responses after influenza vaccination are severely reduced in patients with rheumatoid arthritis treated with rituximab. Arthritis Rheum 62:75-81

68. Bedognetti D, Zoppoli G, Massucco C et al (2011) Impaired response to influenza vaccine associated with persistent memory $B$ cell depletion in non-Hodgkin's lymphoma patients treated with rituximab-containing regimens. J Immunol 186:6044-6055

69. Chen D, Ireland SJ, Davis LS et al (2016) Autoreactive CD19+CD20-plasma cells contribute to disease severity of experimental autoimmune encephalomyelitis. J Immunol 196:1541-1549

70. Tesfa D, Palmblad J (2011) Late-onset neutropenia following rituximab therapy: incidence, clinical features and possible mechanisms. Expert Rev Hematol 4:619-625

71. Rodig SJ, Abramson JS, Pinkus GS et al (2006) Heterogeneous CD52 expression among hematologic neoplasms: implications for the use of alemtuzumab (CAMPATH-1H). Clin Cancer Res 12:7174-7179

72. Möhn N, Pfeuffer S, Ruck Tet al (2020) Alemtuzumab therapy changes immunoglobulin levels in peripheral blood and CSF. Neurol Neuroimmunol Neuroinflamm 7(2):e654. https://doi.org/10.1212/NXI.00000000000000654

73. Hartung H-P, Mares J, Barnett MH (2020) Alemtuzumab: rare serious adverse events of a high-efficacy drug. Mult Scler. https://doi.org/10.1177/ 1352458520913277

74. Brownlee WJ, Chataway J (2017) Opportunistic infections after alemtuzumab: New cases of norcardial infection and cytomegalovirus syndrome. Mult Scler 23:876-877

75. Ghosh S, Goldin E, Gordon FH et al (2003) Natalizumab for active Crohn's disease. NEngl I Med 348:24-32

76. Polman CH, O'Connor PW, Havrdova E et al (2006) A randomized, placebocontrolled trial of natalizumab for relapsing multiple sclerosis. N Engl J Med 354:899-910

77. Yousry TA, Major EO, Ryschkewitsch C et al (2006) Evaluation of patients treated with natalizumab for progressive multifocal leukoencephalopathy. N Engl J Med 354:924-933

78. Pawlitzki M, Teuber J, Campe C et al (2018) VZV-associated acute retinal necrosis in a patient with MS treated with natalizumab. Neurol Neuroimmunol Neuroinflamm 5:e475

79. Niino M, Bodner C, Simard M-L et al (2006) Natalizumab effects on immune cell responses in multiple sclerosis. Ann Neurol 59:748-754

80. Bonig H, Wundes A, Chang K-H et al (2008) Increased numbers of circulating hematopoietic stem/progenitor cells are chronically maintained in patients treated with the CD49d blocking antibody natalizumab. Blood 111:3439-3441
81. Planas R, Jelčićl, Schippling S et al (2012) Natalizumab treatment perturbs memory-and marginal zone-like B-cell homing in secondary lymphoid organs in multiple sclerosis. Eur I Immunol 42:790-798

82. Mameli G, Arru G, Caggiu Eet al (2016) Natalizumab therapy modulates miR-155, miR-26a and proinflammatory cytokine expression in MS patients. PLOS ONE 11:e157153

83. Woodside DG, Vanderslice P (2008) Cell adhesion antagonists: therapeutic potential in asthma and chronic obstructive pulmonary disease. BioDrugs 22:85-100

84. Brinkmann V (2009) FTY720 (fingolimod) in Multiple Sclerosis: therapeutic effects in the immune and the central nervous system. Br J Pharmacol 158:1173-1182

85. Kappos L, Radue E-W, O'Connor P et al (2010) A placebo-controlled trial of oral fingolimod in relapsing multiple sclerosis. N Engl J Med 362:387-401

86. Comi G, Hartung H-P, Bakshi R et al (2017) Benefit-risk profile of sphingosine-1phosphate receptor modulators in relapsing and secondary progressive multiple sclerosis. Drugs 77:1755-1768

87. van Rossum JA, Looysen EE, Daniels JMA et al (2014) Fingolimod-induced asthma deterioration in a patient with relapsing-remitting multiple sclerosis. Mult Scler 20:1792-1793

88. Cyster JG, Schwab SR (2012) Sphingosine-1-phosphate and lymphocyte egress from lymphoid organs. Annu Rev Immunol 30:69-94

89. Idzko M, Hammad H, van Nimwegen M et al (2006) Local application of FTY720 to the lung abrogates experimental asthma by altering dendritic cell function. J Clin Invest 116:2935-2944

90. Zhang X, Liu H, Wang Set al (2019) LncRNA analysis of lung tissues after hUCMSCS and FTY720 treatment of lipopolysaccharide-induced acute lung injury in mouse models. Int Immunopharmacol 71:68-75

91. Wang L, Sammani S, Moreno-Vinasco L et al (2014) FTY720 (s)-phosphonate preserves sphingosine 1-phosphate receptor 1 expression and exhibits superior barrier protection to FTY720 in acute lung injury. Crit Care Med 42:e189-e199

92. Rahman MM, Prünte L, Lebender LF et al (2016) The phosphorylated form of FTY720 activates PP2A, represses inflammation and is devoid of S1P agonism in A549 lung epithelial cells. Sci Rep 6:37297

93. Longbrake EE, Naismith RT, Parks BJ et al (2015) Dimethyl fumarate-associated lymphopenia: risk factors and clinical significance. Mult Scler J Exp TransI Clin . https://doi.org/10.1177/2055217315596994

94. Morales SF, Koralnik IJ, Gautam Set al (2020) Risk factors for lymphopenia in patients with relapsing-remitting multiplesclerosis treated with dimethyl fumarate. J Neurol 267:125-131

95. Zettl UK, Hecker M, Aktas O et al (2018) Interferon $\beta$-1 1 a and $\beta$-16 for patients with multiple sclerosis: updates to current knowledge. Expert Rev Clin Immunol 14:137-153

96. Kasper LH, Reder AT (2014) Immunomodulatory activity of interferon-beta. Ann Clin Trans/ Neurol 1:622-631

97. Jiang $H$ (1995) Interferon $\beta$-lb reduces Interferon $\gamma$-induced antigen-presenting capacity of human glial and B cells. J Neuroimmunol 61:17-25

98. Yong VW (2002) Differential mechanisms of action of interferon-beta and glatiramer aetate in MS. Neurology 59:802-808

99. Boasso A (2009) Type I interferon in HIV treatment: from antiviral drug to therapeutic target. HIV Ther 3:269-282

100. de Wilde AH, Jochmans D, Posthuma CC et al (2014) Screening of an FDAapproved compound library identifies four small-molecule inhibitors of Middle East respiratory syndrome coronavirus replication in cell culture. Antimicrob Agents Chemother 58:4875-4884

101. Kleiter I, Ayzenberg I, Araki M et al (2016) Tocilizumab, MS, and NMOSD. Mult Scler 22:1891-1892

102. Yamamura T, Kleiterl, Fujihara Ket al (2019) Trial of satralizumab in neuromyelitis Optica spectrum disorder. NEngl J Med 381:2114-2124

103. Tanaka T, Narazaki M, Kishimoto T (2014) IL-6 in inflammation, immunity, and disease. Cold Spring Harb Perspect Biol 6:a16295

104. Shimabukuro-Vornhagen A, Gödel P, Subklewe M et al (2018) Cytokine release syndrome. J Immunother Cancer 6:56 
105. Norelli M, Camisa B, Barbiera Get al (2018) Monocyte-derived IL-1 and IL-6 are differentially required for cytokine-release syndrome and neurotoxicity due to CAR Tcells. Nat Med 24:739-748

106. Tanaka T, Narazaki M, Kishimoto T (2016) Immunotherapeutic implications of IL-6 blockade for cytokine storm. Immunotherapy 8:959-970

107. Zheng J, Shi Y, Xiong L et al (2017) The expression of IL-6, TNF-a, and MCP-1 in respiratory viral infection in acute exacerbations of chronic obstructive pulmonary disease. J Immunol Res 2017:8539294

108. Velazquez-Salinas L, Verdugo-Rodriguez A, Rodriguez LL et al (2019) The role of Interleukin 6 during viral infections. Front Microbiol 10:1057

109. Herold T, Jurinovic V, Arnreich C et al (2020) Level of IL-6 predicts respiratory failure in hospitalized symptomatic COVID-19 patients

110. Qin C, Zhou L, Hu Z et al (2020) Dysregulation of immune response in patients with COVID-19 in Wuhan, China. Clin Infect Dis. https://doi.org/10.1093/cid/ ciaa248

111. Gong J, Dong H, Xia SQ et al (2020) Correlation analysis between disease severity and inflammation-related parameters in patients with COVID-19. Pneumonia. https://doi.org/10.1101/2020.02.25.20025643

112. Coomes EA, Haghbayan H (2020) Interleukin-6 in COVID-19: a systematic review and meta-analysis

113. Le RQ, Li L, Yuan W et al (2018) FDA approval summary: tocilizumab for treatment of chimeric antigen receptor $T$ cell-induced severe or life-threatening cytokine release syndrome. Oncologist 23:943-947

114. de Luna G, Habibi A, Deux JF et al (2020) Rapid and severe Covid-19 pneumonia with severe acute chest syndrome in a sickle cell patient successfully treated with Tocilizumab. Am J Hematol. https://doi.org/10.1002/ajh.25833

115. Cellina M, Orsi M, Bombaci Fet al (2020) Favorable changes of CT findings in a patient with COVID-19 pneumonia after treatment with tocilizumab. Diagn Interv Imaging. https://doi.org/10.1016/j.diii.2020.03.010

116. Michot J-M, Albiges L, Chaput N et al (2020) Tocilizumab, an anti-IL6 receptor antibody, to treat Covid-19-related respiratory failure: a case report. Ann Oncol. https://doi.org/10.1016/j.annonc.2020.03.300

117. Zhang C, Wu Z, Li J-W et al (2020) The cytokine release syndrome (CRS) of severe COVID-19 and Interleukin-6 receptor (IL-6R) antagonist Tocilizumab may be the key to reduce the mortality. Int J Antimicrob Agents. https://doi.org/10.1016/j. ijantimicag.2020.105954

118. Sciascia S, Aprà F, Baffa A et al (2020) Pilot prospective open, single-arm multicentre study on off-label use of tocilizumab in severe patients with COVID19. Clin Exp Rheumato/ 38(3):529-532

119. Pittock SJ, Berthele A, Fujihara Ket al (2019) Eculizumab in aquaporin-4-positive neuromyelitis optica spectrum disorder. N Engl J Med 381:614-625

120. Howard JF, Utsugisawa K, Benatar Met al (2017) Safety and efficacy of eculizumab in anti-acetylcholine receptor antibody-positive refractory generalised myasthenia gravis (REGAIN): a phase 3, randomised, double-blind, placebo-controlled, multicentre study. Lancet Neurol 16:976-986

121. Stoermer KA, Morrison TE (2011) Complement and viral pathogenesis. Virology 411:362-373

122. Dunkelberger JR, Song W-C (2010) Role and mechanism of action of complement in regulating T cell immunity. Mol Immunol 47:2176-2186

123. Benamu E, Montoya JG (2016) Infections associated with the use of eculizumab: recommendations for prevention and prophylaxis. Curr Opin Infect Dis 29:319-329

124. Wang R, Xiao H, Guo R et al (2015) The role of C5a in acute lung injury induced by highly pathogenic viral infections. Emerg Microbes Infect 4:e28

125. Bosmann M, Ward PA (2012) Role of C3, C5 and anaphylatoxin receptors in acute lung injury and in sepsis. Adv Exp Med Biol 946:147-159

126. Jiang Y, Zhao G, Song N et al (2018) Blockade of the C5a-C5aR axis alleviates lung damage in hDPP4-transgenic mice infected with MERS-CoV. Emerg Microbes Infect 7:77

127. Elkharrat D, Goulon M, Gajdos P (1987) Cyclosporine for myasthenia gravis. N Engl J Med 317:770
128. Barba T, Fort R, Cottin V et al (2019) Treatment of idiopathic inflammatory myositis associated interstitial lung disease: A systematic review and metaanalysis. Autoimmun Rev 18:113-122

129. Bonifati DM, Angelini C (1997) Long-term cyclosporine treatment in a group of severe myasthenia gravis patients. J Neurol 244:542-547

130. Tanaka Y, Sato Y, Sasaki T (2013) Suppression of coronavirus replication by cyclophilin inhibitors. Viruses 5:1250-1260

131. Ericson JE, Zimmerman KO, Gonzalez D et al (2017) A systematic literature review approach to estimate the therapeutic index of selected immunosuppressant drugs after renal transplantation. Ther Drug Monit 39:13-20

132. Gold R, Buttgereit F, Toyka KV (2001) Mechanism of action of glucocorticosteroid hormones: possible implications for therapy of neuroimmunological disorders. J Neuroimmunol 117:1-8

133. Klein NC, Go CH-U, Cunha BA (2001) Infections associated with steroid use. Infect Dis Clin North Am 15:423-432

134. Le Page E, Veillard D, Laplaud DA et al (2015) Oral versus intravenous high-dose methylprednisolone for treatment of relapses in patients with multiple sclerosis (COPOUSEP): a randomised, controlled, double-blind, non-inferiority trial. Lancet 386:974-981

135. Nicastri E, Petrosillo N, Bartoli TA et al (2020) National Institute for the Infectious Diseases "L. Spallanzani", IRCCS. Recommendations for COVID-19 clinical management. Infect Dis Rep 12:8543

136. Yang Z, Liu J, Zhou Y et al (2020) The effect of corticosteroid treatment on patients with coronavirus infection: a systematic review and meta-analysis. J Infect. https://doi.org/10.1016/j.jinf.2020.03.062

137. Russell CD, Millar JE, Baillie JK (2020) Clinical evidence does not support corticosteroid treatment for 2019-nCoV lung injury. Lancet 395:473-475

138. Xu Z, Shi L, Wang Y et al (2020) Pathological findings of COVID-19 associated with acute respiratory distress syndrome. Lancet Respir Med 8:420-422

139. Lünemann JD, Nimmerjahn F, Dalakas MC (2015) Intravenous immunoglobulin in neurology - mode of action and clinical efficacy. Nat Rev Neurol 11:80-89

140. Ichiyama T, Ueno Y, Hasegawa Met al (2004) Intravenous immunoglobulin inhibits NF-kappaB activation and affects Fcgamma receptor expression in monocytes/macrophages. Naunyn Schmiedebergs Arch Pharmacol 369:428-433

141. Araujo LM, Chauvineau A, Zhu Ret al (2011) Cutting edge: intravenous Ig inhibits invariant NKT cell-mediated allergic airway inflammation through FCYRIIIAdependent mechanisms. J Immunol 186:3289-3293

142. Ichiyama T, Ueno Y, Isumi Het al (2004) An immunoglobulin agent (IVIG) inhibits NF-kappaB activation in cultured endothelial cells of coronary arteries in vitro. Inflamm Res 53:253-256

143. Macmillan HF, Rowter D, Lee Tet al (2010) Intravenous immunoglobulin G selectively inhibits IL-1a-induced neutrophil-endothelial cell adhesion. Autoimmunity 43:619-627

144. Aukrust P, Müller F, Svenson M et al (1999) Administration of intravenous immunoglobulin (IVIG) in vivo-down-regulatory effects on the IL-1 system. Clin Exp Immunol 115:136-143

145. Seite J-F, Shoenfeld Y, Youinou P et al (2008) What is the contents of the magic draft IVlg? Autoimmun Rev 7:435-439

146. Basta M, van Goor F, Luccioli S et al (2003) F(ab)'2-mediated neutralization of C3a and C5a anaphylatoxins: a novel effector function of immunoglobulins. Nat Med 9:431-438

147. Konrad S, Baumann U, Schmidt RE et al (2006) Intravenous immunoglobulin (IVIG)-mediated neutralisation of C5a: a direct mechanism of IVIG in the maintenance of a high FC gammaRIIB to FC gammaRIII expression ratio on macrophages. Br J Haematol 134:345-347

148. Xu C, Poirier B, van Duong Huyen J-P et al (1998) Modulation of endothelial cell function by normal polyspecific human intravenous Immunoglobulins. Am J Pathol 153:1257-1266

149. Kreymann $K G$, de Heer $G$, Nierhaus A et al (2007) Use of polyclonal immunoglobulins as adjunctive therapy for sepsis or septic shock. Crit Care Med 35:2677-2685 
150. Rolfes L, Pfeuffer S, Ruck T et al (2019) Therapeutic apheresis in acute relapsing multiple sclerosis: current evidence and unmet needs-a systematic review. JCM 8:1623

151. Knaup H, Stahl K, Schmidt BMW et al (2018) Early therapeutic plasma exchange in septic shock: a prospective open-label nonrandomized pilot study focusing on safety, hemodynamics, vascular barrier function, and biologic markers. Crit Care 22:285

152. Rimmer E, Houston BL, Kumar A et al (2014) The efficacy and safety of plasma exchange in patients with sepsis and septic shock: a systematic review and metaanalysis. Crit Care 18:699

153. Ransohoff RM, Hafler DA, Lucchinetti CF (2015) Multiple sclerosis-a quiet revolution. Nat Rev Neurol 11:134-142

154. Sanders DB, Evoli A (2010) Immunosuppressive therapies in myasthenia gravis. Autoimmunity 43:428-435

155. Haberman R, Axelrad J, Chen A et al (2020) Covid-19 in immune-mediated inflammatory diseases - case series from New York. N Engl J Med. https:// doi.org/ 10.1056/NEJMc2009567

156. Clerico M, de Mercanti SF, Signori A et al (2020) Extending the interval of natalizumab dosing: is efficacy preserved? Neurotherapeutics 17:200-207

157. Ellrichmann G, Bolz J, Peschke M et al (2019) Peripheral CD19+B-cell counts and infusion intervals as a surrogate for long-term B-cell depleting therapy in multiple sclerosis and neuromyelitis optica/neuromyelitis optica spectrum disorders. J Neurol 266:57-67

158. Vågberg M, Kumlin U, Svenningsson A (2012) Humoral immune response to influenza vaccine in natalizumab-treated MS patients. Neurol Res 34:730-733

159. Mehling $M$, Hilbert $P$, Fritz S et al (2011) Antigen-specific adaptive immune responses in fingolimod-treated multiple sclerosis patients. Ann Neurol 69:408-413

160. Olberg HK, Eide GE, Cox RJ et al (2018) Antibody response to seasonal influenza vaccination in patients with multiple sclerosis receiving immunomodulatory therapy. Eur J Neurol 25:527-534

161. Wiwanitkit V (2010) Safety of influenza vaccination: risk-benefit evaluation. Muscle Nerve 42:296 (author reply 296.)

162. Schwid SR, Decker MD, Lopez-Bresnahan M (2005) Immune response to influenza vaccine is maintained in patients with multiple sclerosis receiving interferon beta1a. Neurology 65:1964-1966

163. Bar-Or A, Freedman MS, Kremenchutzky M et al (2013) Teriflunomide effect on immune response to influenza vaccine in patients with multiple sclerosis. Neurology 81:552-558

164. von Hehn C, Howard J, Liu S et al (2018) Immune response to vaccines is maintained in patients treated with dimethyl fumarate. Neurol Neuroimmunol Neuroinflamm 5:e409

165. McCarthy CL, Tuohy O, Compston DAS et al (2013) Immune competence after alemtuzumab treatment of multiple sclerosis. Neurology 81:872-876

166. Zrzavy T, Kollaritsch H, Rommer PS et al (2019) Vaccination in multiple sclerosis: friend or foe? Front Immunol 10:1883

167. Rolfes L, Pawlitzki M, Pfeuffer Set al (2019) Fulminant MS reactivation following combined Fingolimod cessation and yellow fever vaccination. IJMS 20:5985. https://doi.org/10.3390/ijms20235985

168. Loebermann M, Winkelmann A, Hartung H-P et al (2012) Vaccination against infection in patients with multiple sclerosis. Nat Rev Neurol 8:143-151

169. Abbas AK, Lichtman AH, Pillai S (2018) Cellular and molecular immunology. Elsevier, Philadelphia
Korrespondenzadresse

\section{Dr. Marc Pawlitzki}

Klinik für Neurologie mit Institut für Translationale

Neurologie

Universitätsklinikum Münster

Albert-Schweitzer-Campus 1, 48149 Münster,

Deutschland

marc.pawlitzki@ukmuenster.de

\section{Einhaltung ethischer Richtlinien}

Interessenkonflikt. M. Pawlitzki: Erstattung von Reise-, Unterbringungs-, sowie Sitzungskosten durch Novartis. U.K. Zettl: Vortragshonorare und Reisekostenerstattung für Meetings durch Alexion, Almirall, Bayer Health Care, Biogen, Celgene, Genzyme, Merck Serono, Novartis, Roche, Sanofi-Aventis und Teva. Seine Forschungsprojekte werden gefördert vom Bundesministerium für Bildung und Forschung (BMBF), vom Bundesministeriums für Wirtschaft und Energie (BMWi), von der Deutschen Forschungsgemeinschaft (DFG) und der Europäischen Union (EU). T. Ruck erhielt bisher Zuschüsse vom Bundesministerium für Bildung und Forschung (BMBF). Desweiteren erhielt er Zuschüsse und Honorare von Sanofi-Genzyme, Biogen, Merck Serono, Roche und Teva sowie nichtfinanzielle Unterstützung von Merck Serono. L. Rolfes hat Reisekostenerstattung durch Merck Serono, Sanofi Genzyme und Roche erhalten. H.-P. Hartung hat Honorare für Beratung und Mitarbeit in Lenkungs- und Datenüberwachungsausschüssen durch Bayer Healthcare, Biogen, CSL Behring, Celgene Receptos, GeNeuro, MedDay, Medlmmune, Merck, Novartis, Octapharma, Roche, Teva, TG Therapeutics und VielaBio erhalten. S.G. Meuth hat Vortragshonorare und Reisekostenerstattung von Almirall, Amicus Therapeutics Germany, Bayer Health Care, Biogen, Celgene, Diamed, Genzyme, MedDay Pharmaceuticals, Merck Serono, Novartis, Novo Nordisk, ONO Pharma, Roche, Sanofi-Aventis, Chugai Pharma, QuintilesIMS und Teva erhalten. Seine Forschungsprojekte werden gefördert vom Bundesministerium für Bildung und Forschung (BMBF), der Deutschen Forschungsgemeinschaft (DFG), der Else Kröner-Fresenius-Stiftung (EKFS), dem Deutschen Akademischen Austauschdienst, der HertieStiftung, dem Interdisziplinären Zentrum für Klinische Forschung Münster (IZKF), der Deutschen Stiftung Neurologie sowie von Almirall, Amicus Therapeutics Germany, Biogen, Diamed, Fresenius Medical Care, Genzyme, Merck Serono, Novartis, ONO Pharma, Roche und Teva.

Für diesen Beitrag wurden von den Autoren keine Studien an Menschen oder Tieren durchgeführt. Für die aufgeführten Studien gelten die jeweils dort angegebenen ethischen Richtlinien. 